\title{
Improved survival of microencapsulated islets during in vitro culture and enhanced metabolic function following transplantation
}

\author{
G. S. Korbutt ${ }^{1,2}$ - A. G. Mallett $\mathrm{H}^{1,2}$-Z. Ao ${ }^{3}$ M. Flashner $^{4}$ R. V. Rajotte ${ }^{1,2,5}$ \\ ${ }^{1}$ Surgical-Medical Research Institute, Dentistry/Pharmacy Building, University of Alberta, Edmonton, Alberta, \\ Canada \\ 2 Department of Surgery, University of Alberta, Edmonton, Canada \\ 3 UBC/VGH Clinical Islet Lab, University of British Columbia, Vancouver, Canada \\ ${ }^{4}$ EGB Advisors, LLC, San Francisco, California, USA \\ ${ }^{5}$ Department of Medicine, University of Alberta, Edmonton, Canada
}

\section{Abstract}

Aims/hypothesis. The aim of this study was to determine whether a simple alginate capsule can prolong islet survival and function during long-term tissue culture. We also wanted to observe the ability of these encapsulated islets to restore glucose responsiveness to diabetic recipients, along with the quantity of islets required to do so.

Methods. We compared the recovery and metabolic function of encapsulated canine islets with that of non-encapsulated canine islets following 1, 2 or 3 weeks of tissue culture. These culture preparations were also transplanted into diabetic nude mice and compared for their ability to reverse diabetes. Furthermore, short-term cultured encapsulated and nonencapsulated islets were transplanted in varying numbers to determine the minimum dose required to normalise blood glucose and prolong recipient survival.
Results. Islet recovery following 1, 2 and 3 weeks of tissue culture was significantly higher when islets were encapsulated. When these islets were recovered at 1,2 and 3 weeks and transplanted into diabetic nude mice, survival at 100 days was $100 \%$ for all encapsulated groups, versus $66 \%, 33 \%$ and $33 \%$ respectively for the non-encapsulated islets. Additionally, substantially fewer short-term cultured islets were required to normalise blood glucose when the islets were encapsulated. Recipients of encapsulated islets also had significantly longer survival times than recipients of non-encapsulated preparations.

Conclusions/interpretation. This study demonstrates that encapsulation of islets with purified alginate improves islet survival and function in vitro and in vivo.

Keywords Alginate - Capsules - Diabetes - Dogs ·

Insulin · Islet transplantation · Mice ·

Microencapsulation · Tissue culture $\cdot$ Transplantation
Received: 15 April 2004 / Accepted: 13 July 2004

Published online: 23 October 2004

(C) Springer-Verlag 2004

R. V. Rajotte (®)

Surgical-Medical Research Institute,

1074 Dentistry/Pharmacy Building, University of Alberta,

Edmonton, Alberta, Canada T6G 2N8

E-mail: rrajotte@ualberta.ca

Tel.: +1-780-4923386, Fax: +1-780-4921627

Abbreviations: CMRL, Connaught Medical Research Laboratories media · HBSS, Hank's balanced salt solution · IE, islet equivalents

Conflict of interest: No conflict of interest has been declared by the authors.

\section{Introduction}

Advances in clinical islet transplantation have focused attention on islet transplantation as a potential therapy in the management of Type 1 diabetes [1]. However, this therapy has not been beneficial to diabetic patients at large, due to two major obstacles. First, the shortage of cadaveric human pancreases limits the availability of donor tissue for transplantation. Currently islets from multiple donors are required to effectively establish normoglycaemia in diabetic recipients. Long-term culture has been considered as a potential way of accruing a suitable mass of islets for transplantation from multiple donors $[2,3]$. Unfortunately, long-term islet culture often results in a significant loss of islet mass and viability. Biocompatible 
matrixes such as sodium alginate have been used as a means of reducing the detrimental effects of long-term culture $[4,5,6]$.

The second barrier to islet transplantation as a widespread therapy is the current need for chronic immunosuppression to prevent graft rejection [7]. To overcome this hurdle, microencapsulation of allogeneic or xenogeneic islet grafts has been proposed as a means of protecting islets from immune mediated destruction $[8,9,10,11]$. The literature reveals, however, that success has so far been limited and non-reproducible. It is thought that the inability of encapsulated islet grafts to reproducibly achieve and maintain long-term euglycaemia is related not only to insufficient immunoprotection, but also to a variety of technical and metabolic issues, including: the encapsulation process, composition/purity of the microcapsule [12], capsule size and surface structure [13, 14], poor biocompatibility $[15,16]$, and endotoxin levels of the alginate $[17,18]$. Furthermore, while the addition of poly-L-lysine has been used to reduce capsule porosity [19], its addition has resulted in an increased fibrotic response [15]. Recently, it has been shown that a simple alginate capsule devoid of poly-L-lysine retains the ability to prolong graft survival and protect the graft [6].

The aim of this study was to determine whether islets encapsulated in a highly purified calcium-alginate capsule exhibit prolonged survival and function during long-term tissue culture and post-transplantation. We used immuno-incompetent mice implanted with canine islets, as well as syngeneic mouse islet grafts in which a potential fibrotic response could be examined.

\section{Materials and methods}

Experimental design. The survival and function of encapsulated canine islets were examined in vitro and in vivo. Controls included non-encapsulated islets. Islets were cultured for 1, 2 and 3 weeks and were compared with respect to islet recovery, glucose-stimulated insulin secretion and metabolic function following transplantation. Experiments compared the success and longevity of transplants using varying masses of encapsulated or non-encapsulated canine islets in nude mice. Another set of experiments determined the efficacy of encapsulated syngeneic mouse islets transplanted intraperitoneally to immunocompetent mice to assess graft survival in a model able to exhibit an inflammatory response.

Animals. Donor pancreases were obtained from mongrel dogs (University of Alberta, Edmonton, Alberta, Canada) of either sex, weighing 9-30 kg, that had previously been anaesthetised with halothane. Male, inbred, athymic nude BALB/c mice (age 6-8 weeks) (Jackson Laboratories, Bar Harbor, Mass., USA) were used as recipients of the canine islets. Male Balb/c mice (University of Alberta) were used as donors and recipients for syngeneic grafts. Mice were rendered diabetic by intravenous injection of alloxan $(90 \mathrm{mg} / \mathrm{kg}$ body weight; Sigma Chemical, St. Louis, Mo., USA) freshly dissolved in $1 \mathrm{mmol} / 1$ hydrochloric acid 7 to 10 days before transplantation. Recipients exhibit- ed blood glucose levels above $20 \mathrm{mmol} / \mathrm{l}$. Blood samples were obtained from the tail vein for glucose assay (Medisense glucose meter, Medisense Canada, Mississauga, Ont., Canada). Animals were maintained under virus-antibody-free conditions in climatised rooms with free access to sterilised tap water and pelleted food.

Preparation and microencapsulation of islets. Canine islets were retrieved through pancreatectomy, islet isolation by collagenase (type V, Sigma) digestion and purification on discontinuous Ficoll (Sigma) density gradients [20, 21]. The mean number of islets in each of six diameter ranges from 60 to $350 \mu \mathrm{m}$ was determined in order to convert the total yield into $150-\mu \mathrm{m}$ diameter islet equivalents (IE) [22]. Islets were then distributed in groups of 5000 IE per non-treated bacteriological Petri dish (15 cm diameter; Fisher Scientific, Ottawa, Ont, Canada), suspended in $35 \mathrm{ml}$ of Connaught Medical Research Laboratories (CMRL) 1066 tissue culture medium (Gibco, Burlington, Ont., Canada) that was supplemented with $5.6 \mathrm{mmol} / \mathrm{l}$ glucose, $2 \mathrm{mmol} / \mathrm{l} \mathrm{L}$-glutamine, $10 \%$ (v/v) fetal calf serum (Gibco), $100 \mathrm{U} / \mathrm{ml}$ penicillin and $100 \mu \mathrm{g} / \mathrm{ml}$ streptomycin, and cultured overnight in humidified air $\left(5 \% \mathrm{CO}_{2}, 95 \%\right.$ air $)$ at $22{ }^{\circ} \mathrm{C}$.

Mouse islets were isolated by collagenase (type V, Sigma) digestion of the pancreas [23], purified using discontinuous Ficoll (Sigma) density gradients, hand-picked and suspended in supplemented CMRL 1066, after which they were cultured overnight at $22{ }^{\circ} \mathrm{C}$ in humidified air $\left(5 \% \mathrm{CO}_{2}, 95 \%\right.$ air $)$.

After culture, aliquots of approximately 10,000 canine IE or 3000 to 5000 mouse islets were washed and resuspended in $0.44 \mathrm{ml}$ of Hank's balanced salt solution (HBSS) (Gibco) that was free of $\mathrm{Ca}^{++}$and $\mathrm{Mg}^{++}$. They were then mixed with $0.55 \mathrm{ml}$ of $1.5 \%(\mathrm{w} / \mathrm{v})$ highly purified, high guluronic content alginate (high $\mathrm{G}$ alginate, $72 \% \mathrm{G}$-content, $28 \%$ M-content, 193,800 MW, endotoxins 0.25 IU/ml; Metabolex, Hayward, Calif., USA) dissolved in HBSS (without $\mathrm{Ca}^{++}, \mathrm{Mg}^{++}$) $(\mathrm{pH} 7.4)$. Alginate microcapsules (250-350 $\mu \mathrm{m}$ in diameter) were formed using an electrostatic droplet generator (designed by Metabolex). Capsules were then cultured in supplemented CMRL medium at $22{ }^{\circ} \mathrm{C}$ for 1,2 or 3 weeks.

Characterisation of canine islet preparations after long-term tissue culture. After 1, 2 or 3 weeks of culture at $22{ }^{\circ} \mathrm{C}$, canine islet preparations were re-counted to determine total IE recovery and assessed for functional viability. These islets were washed in HBSS and transferred to supplemented CMRL 1066 medium for $24 \mathrm{~h}$ of culture at $37^{\circ} \mathrm{C}$. The islets' insulin secretory responsiveness to glucose was determined during a 2-h static incubation at $37^{\circ} \mathrm{C}$ [24]. Samples of 50 IE were incubated in 24-well non-tissue culture treated plates (Becton Dickson Labware, Franklin Lakes, N.J., USA) with $1.5 \mathrm{ml}$ of RPMI medium (Gibco) supplemented with $2 \mathrm{mmol} / \mathrm{l}$ L-glutamine, $0.5 \% \mathrm{BSA}$ and either $2.8 \mathrm{mmol} / \mathrm{l}$ or $20 \mathrm{mmol} / \mathrm{l}$ glucose. The insulin content of the medium was expressed as a percentage of the total content (i.e. tissue plus medium). Stimulation indices were calculated by dividing the amount of insulin release at $20 \mathrm{mmol} / \mathrm{l}$ glucose by that released at $2.8 \mathrm{mmol} / \mathrm{l}$ glucose.

Transplantation and metabolic follow-up. In long-term culture experiments, non-encapsulated and encapsulated canine islets were transplanted (renal subcapsule and intraperitoneal implant respectively) following 1, 2 or 3 weeks of culture into diabetic nude mice that had been anaesthetised with halothane. In short-term culture experiments, freshly isolated canine islets were cultured for 24 hours, encapsulated, then cultured overnight in supplemented CMRL. Varying masses of islets were transplanted under the renal subcapsule (non-encapsulated) or in the peritoneal cavity (non-encapsulated or encapsulat- 
Table 1. Effect of microencapsulation on canine islet recovery and insulin secretory activity over a 3-week period in culture

\begin{tabular}{|c|c|c|c|c|}
\hline \multirow[b]{2}{*}{ Condition } & \multirow[b]{2}{*}{ Islet recovery $(\%)$} & \multicolumn{2}{|c|}{ Insulin secretory activity ( $\%$ content) } & \multirow{2}{*}{$\begin{array}{l}\text { Stimulation indices } \\
\text { High : low }\end{array}$} \\
\hline & & $2.8 \mathrm{mmol} / \mathrm{l}$ glucose & $20 \mathrm{mmol} / \mathrm{l}$ glucose & \\
\hline 1 week $(n=5)$ & $63.2 \pm 5.3$ & $0.55 \pm 0.06$ & $10.1 \pm 0.2$ & $18.7 \pm 1.8$ \\
\hline 2 weeks $(n=6)$ & $55.5 \pm 4.2$ & $0.97 \pm 0.11^{\mathrm{c}}$ & $9.4 \pm 0.4$ & $9.7 \pm 0.4^{c}$ \\
\hline 3 weeks $(n=4)$ & $24.5 \pm 10.2^{\mathrm{c}}$ & $1.07 \pm 0.11^{\mathrm{c}}$ & $9.2 \pm 0.2$ & $8.8 \pm 0.7^{c}$ \\
\hline 1 week $(n=6)$ & $97.3 \pm 2.6^{b}$ & $0.43 \pm 0.06$ & $8.7 \pm 0.4$ & $20.8 \pm 2.0$ \\
\hline 2 weeks $(n=7)$ & $89.6 \pm 4.2^{b}$ & $0.54 \pm 0.04^{b}$ & $9.5 \pm 0.3$ & $17.6 \pm 1.4^{\mathrm{a}}$ \\
\hline 3 weeks $(n=4)$ & $71.4 \pm 7.6^{\mathrm{a}, \mathrm{d}}$ & $0.87 \pm 0.04^{\mathrm{d}}$ & $8.7 \pm 0.1$ & $10.1 \pm 0.4^{\mathrm{d}}$ \\
\hline
\end{tabular}

Values are means \pm SE. Islet recovery is expressed as the percentage of islets remaining after 1, 2 and 3 weeks of culture as compared to day 0 . Islet insulin release experiments were percondition. Insulin secretory activity is expressed as percentage content, given $20.0 \pm 3.1 \mathrm{ng}$ insulin per dog islet (no differences amongst conditions). Stimulation indices were calculated by formed in a minimum of four independent experiments per

dividing the amount of insulin release at high glucose $(20 \mathrm{mmol} / \mathrm{l})$ by that released at low $(2.8 \mathrm{mmol} / \mathrm{l})$ glucose. a $p<0.05 ;{ }^{\mathrm{b}} p<0.001$ vs non-encapsulated at same time period (unpaired Student's $t$ test); ${ }^{c} p<0.01$ vs non-encapsulated at 1 week; d $p<0.01$ vs encapsulated at 1 week (analysis of variance)

\section{Results}

o standardise the mass of canine islets transplanted each experiment, representative aliquots of each preparation were counted prior to implantation to determine total islet equivalents. Grafts consisted of 1000 or 2000 canine IE for long-term culture experiments, while studies of grafts comparing transplanted islet mass varied between 250 to 4000 canine IE. For syngeneic mouse grafts, 500 non-encapsulated (renal subcapsular implant) or encapsulated (intraperitoneal implant) mouse islets were transplanted into diabetic recipients. All grafts were suspended in supplemented CMRL 1066 medium and then implanted either into the peritoneal cavity via a small incision in the linea alba, or under the left renal capsule with the aid of a micromanipulator syringe [24].

Mice were monitored for blood glucose levels between 8.00 and 11.00 hours. When the blood glucose level was $8.4 \mathrm{mmol} / 1$ or less, the graft was deemed a success. At 100 to 120 days after transplantation, OGTTs were performed on recipients with normalised basal glycaemia and in normal controls. After a 2-h fast, D-glucose ( $3 \mathrm{mg} / \mathrm{g}$ body weight) was administered as a $50 \%$ solution by oral gavage into non-anaesthetised mice. Blood samples were obtained from the tail vein at $0,15,30,60$ and $120 \mathrm{~min}$.

At various time points (i.e. at 100 days or more after transplantation) capsules were recovered by intraperitoneal lavage with phosphate-buffered saline containing $12 \mathrm{mmol} / \mathrm{l} \mathrm{CaCl}_{2}$. Recovered grafts were subsequently stained with dithizone. To confirm the efficacy with which encapsulated islets corrected diabetes, the pancreas of each recipient was assayed for insulin content as previously described [24]. Animals with renal subcapsular grafts had the kidney removed and were subsequently monitored to confirm a return to hyperglycaemia.

Statistical analysis. Data are expressed as means \pm SE of $n$ independent observations. Statistical significance of differences was calculated with a two-tailed unpaired Student's $t$ test or one-way analysis of variance in the event of multiple comparisons. Findings were deemed significant at a $p$ value of less than 0.05 .
Canine islet microencapsulation. Immediately following the encapsulation process, islet recovery was $92 \pm 2 \%$ ( $n=10$ independent isolations). In eight independent experiments, the volume of representative aliquots of encapsulated canine islets was estimated in $15-\mathrm{ml}$ Falcon centrifuge tubes. The volume of non-encapsulated preparations was calculated as previously defined [22]. The mean volume of 4000 encapsulated and non-encapsulated IE was $160 \pm 16 \mu \mathrm{l}$ and $7.2 \pm 0.8 \mu \mathrm{l}$ respectively. When 4000 encapsulated IE were hand-picked to eliminate empty capsules the average volume was $150 \pm 8 \mu \mathrm{l}$, demonstrating that approximately $94 \%$ of the capsules contained islets.

Effect of microencapsulation on canine islet survival and insulin secretory activity in vitro. The number of encapsulated islets recovered throughout the various culture periods was significantly higher than for nonencapsulated control islets incubated for the same time (Table 1). The recovery of encapsulated islets was 54, 61 and 190\% higher than for controls following 1,2, and 3 weeks of culture respectively (Table 1). When compared to the start of the experiment, total islet yield of non-encapsulated controls decreased to 63,55 and $25 \%$ after 1,2 and 3 weeks of culture respectively ( $p<0.0001$ at all time points). On the other hand, islet loss was substantially reduced when the islets were encapsulated, with 97,90 and $71 \%$ recovery of islet equivalents after 1,2 and 3 weeks of culture respectively $(p<0.01)$.

The insulin secretory activity of control and encapsulated islets was tested by determining the percentages of cellular insulin that was released at low $(2.8 \mathrm{mmol} / \mathrm{l})$ and high glucose $(20 \mathrm{mmol} / \mathrm{l})$ during a 
Table 2. Effect of long-term culture on the survival of canine islet grafts in diabetic nude mice

$$
\text { Culture period, weeks } \quad \text { Days of euglycaemia, }(\mathrm{MST} \pm \mathrm{SE})
$$

$\%$ Survival, (>100 days)

Graft

Non-encapsulated ${ }^{\mathrm{a}}$

$2000 \mathrm{IE}$

1
2
3

Encapsulated $^{\mathrm{b}}$

\begin{tabular}{ll}
1000 IE's & 1 \\
& 2 \\
2000 IE's & 3 \\
& 1 \\
& 2 \\
\hline
\end{tabular}

$$
\begin{aligned}
& 0,134 \times 2^{c}(89 \pm 45) \\
& 0,80,201^{c}(94 \pm 58) \\
& 0,23,312^{c}(112 \pm 100)
\end{aligned}
$$

66

33

33

$\begin{array}{lr}134^{\mathrm{c}}, 169^{\mathrm{d}}, 170^{\mathrm{d}}, 223^{\mathrm{d}}(174 \pm 18) & 100 \\ 24,107,198 \times 2^{\mathrm{c}}(132 \pm 42) & 75 \\ 147,171^{\mathrm{d}}, 190^{\mathrm{c}}(169 \pm 12) & 100 \\ 109^{\mathrm{d}}, 134^{\mathrm{c}}, 170^{\mathrm{c}}, 198 \times 2^{\mathrm{c}}, 255^{\mathrm{c}}(177 \pm 21) & 100 \\ 180 \times 2^{\mathrm{d}}, 185^{\mathrm{d}}(181 \pm 2) & 100 \\ 162^{\mathrm{c}}, 190^{\mathrm{c}}, 248^{\mathrm{c}}(200 \pm 25) & 100\end{array}$

Euglycaemia was defined as blood glucose values $\leq 8.4 \mathrm{mmol} / \mathrm{l}$. IE, islet equivalents; MST, mean standard time.

a Renal subcapsular transplants; b intraperitoneal transplants;

2-h static incubation assay. After 1 week of culture, no statistically significant differences were observed in the amount of insulin released between the two groups (Table 1). Control and encapsulated islets released more than 18 -fold more insulin at high glucose than at low glucose. These values were similar to freshly isolated non-encapsulated canine islets cultured for $24 \mathrm{~h}$ at $37{ }^{\circ} \mathrm{C}(0.41 \pm 0.02 \%$ and $8.9 \pm 0.03 \%$ at 2.8 and $20 \mathrm{mmol} / \mathrm{l}$ glucose respectively; data not shown). Control islets cultured for 2 or 3 weeks released higher levels $(p<0.001)$ of insulin in response to $2.8 \mathrm{mmol} / \mathrm{l}$ glucose than observed after 1 week of culture. Hence, stimulation indices were significantly lower when control islets were cultured for periods longer than 1 week. In contrast, encapsulated islets showed similar insulin secretory responses when cultured for 1 or 2 weeks (Table 1), while increased insulin release at low glucose was observed only at 3 weeks of culture. Thus, for our encapsulated islets, the calculated stimulation index dropped significantly at 3 weeks of culture.

Transplantation of long-term cultured canine islets. Control or encapsulated canine islets preserved for 1 , 2 and 3 weeks at $22{ }^{\circ} \mathrm{C}$ were transplanted either under the renal capsule or into the intraperitoneal cavity respectively of diabetic nude mice. Transplantation under the renal capsule of 2000 non-encapsulated islets cultured for 1 week corrected diabetes in two of three recipients for more than 100 days. However, when culture was prolonged to 2 or 3 weeks (Table 2), only one of three recipients maintained normoglycaemia for more than 100 days. In contrast, all animals implanted intraperitoneally with 2000 encapsulated islets cultured for 1 to 3 weeks exhibited blood glucose values of $8.4 \mathrm{mmol} / \mathrm{l}$ or less for more than 100 days (Table 2). When 1000 encapsulated islets cultured for c grafts recovered from normoglycaemic recipients for morphological assessment; ${ }^{\mathrm{d}}$ animal died when normoglycaemic

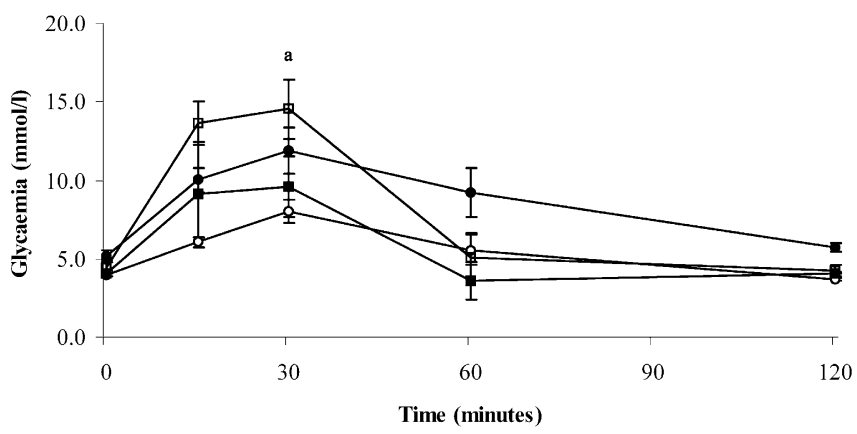

Fig. 1. Blood glucose values during an OGTT in nude mice transplanted with 1000 encapsulated canine islets cultured for $1(\bigcirc ; n=4), 2(\square ; n=3)$, and $3(\square ; n=3)$ weeks. Values are compared to aged-matched normal controls $(\mathbf{O} ; n=9)$ and expressed as means \pm SEM. Statistical significance of differences was calculated by one-way analysis of variance. ${ }^{\mathrm{a}} p<0.05$ vs 1 week of culture

1,2 and 3 weeks were transplanted, $100 \%(4 / 4), 75 \%$ $(3 / 4)$, and $100 \%(3 / 3)$ of the recipients achieved euglycaemia for more than 100 days.

At 100 days after transplantation, OGTTs were performed in aged-matched normal controls and intraperitoneal recipients of 1000 encapsulated islets. OGTTs were not performed in animals implanted with non-encapsulated grafts due to the poor survival after 100 days. Compared to controls, animals receiving 1000 encapsulated islets cultured for 1, 2 and 3 weeks exhibited similar glycaemic values at all time points (Fig. 1). Mice transplanted with canine islets cultured for 3 weeks exhibited mean blood glucose values at 15 and $30 \mathrm{~min}$ that were significantly higher than those in animals implanted with grafts cultured for 1 week. In all groups, blood glycaemia values at 120 min were not significantly different from the values at $0 \mathrm{~min}$. The pancreatic insulin content of all recipients of intraperitoneal implants was less than $2 \%$ 
Table 3. Metabolic follow-up of non-encapsulated and encapsulated canine islet grafts in diabetic nude mice

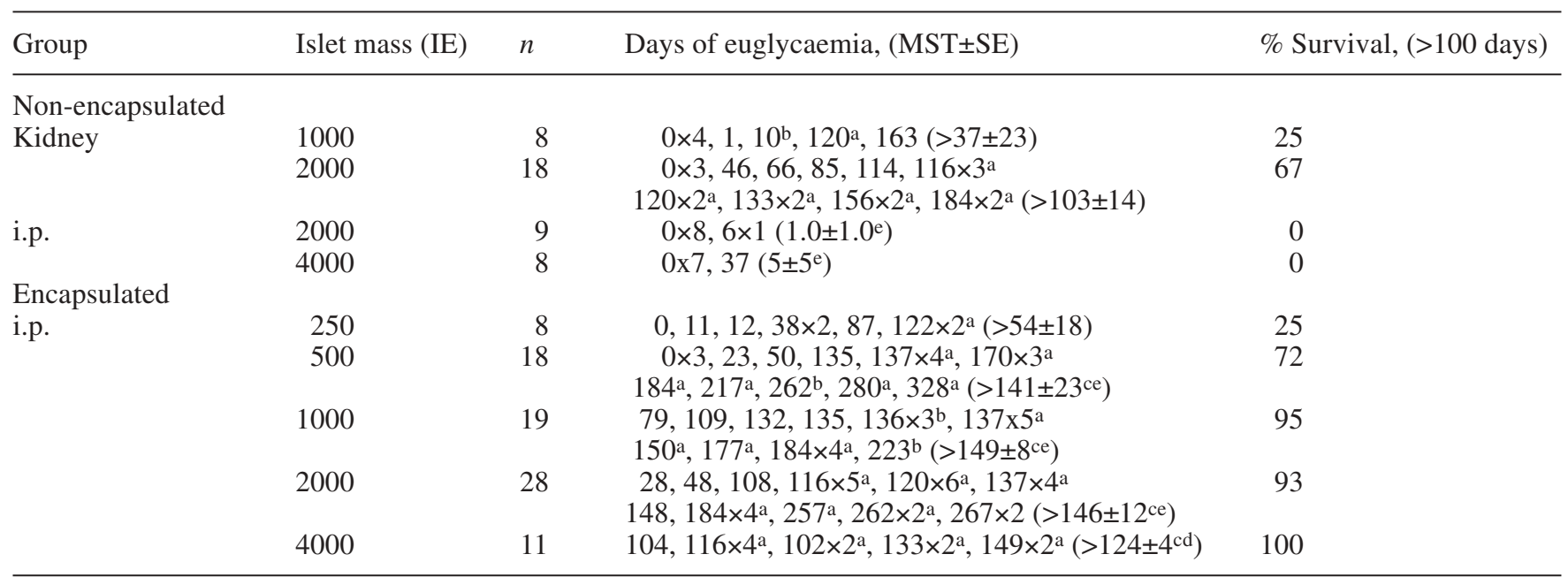

Euglycaemia was defined as blood glucose values $\leq 8.4 \mathrm{mmol} / \mathrm{l}$. IE, islet equivalents; MST, mean standard time. ${ }^{\text {a }}$ Grafts recovered from normoglycaemic recipients for morphological assessment; ${ }^{b}$ animal died while normoglycaemic. Sta-

$(0.49 \pm 0.03 \mu \mathrm{g})$ of that of normal control animals $(38.9 \pm 1.8 \mu \mathrm{g})$, indicating that the grafts were responsible for the euglycaemia. Similarly, removal of the graft-bearing kidneys from normoglycaemic animals was followed by a rapid return to the diabetic state.

Effect of canine islet mass and transplant site. In another series of experiments we assessed what minimal mass of non-encapsulated and encapsulated islets that had been cultured for $48 \mathrm{~h}$ was required to reverse diabetes in nude mice, following transplantation under the kidney capsule or intraperitoneally. Implantation of 1000 and 2000 non-encapsulated islets under the renal subcapsular space corrected basal glucose levels in $50 \%(4 / 8)$ and $83 \%(15 / 18)$ of the animals respectively (Table 3). However, later than 100 days after transplantation, euglycaemia remained in only $25 \%$ $(2 / 8)$ and $67 \%(12 / 18)$ of the 1000- and 2000-islet group respectively. Intraperitoneal transplantation of either 2000 or 4000 non-encapsulated islets had little effect on correcting diabetes, as less than $15 \%$ of the animals exhibited normoglycaemia, which only lasted a short time (Table 3). In contrast, normalisation of blood glucose occurred in $100 \%$ of recipients receiving intraperitoneal grafts of 1000, 2000 and 4000 encapsulated islets (Table 3). In these three groups, basal normoglycaemia was maintained in $95 \%, 93 \%$ and $100 \%$ of the animals for more than 100 days after transplant. When the mass of the intraperitoneal grafts was decreased to 500 and 250 encapsulated islets, $72 \%(13 / 18)$ and $25 \%(2 / 8)$ of the recipients respectively maintained euglycaemia for periods greater than 100 days.

Glucose tolerance tests were performed in normoglycaemic recipients and non-diabetic control mice at tistical significance of differences between groups was calculated by factorial two-way analysis of variance. ${ }^{c} p<0.01$ vs non-encapsulated kidney (1000 IE); ${ }^{\mathrm{d}} p<0.05$; e $p<0.01$ vs nonencapsulated kidney (2000 IE)

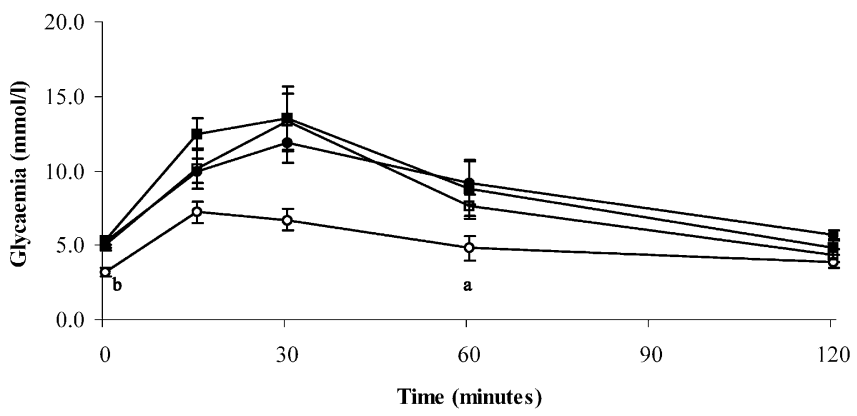

Fig. 2. Blood glucose values during an OGTT in nude mice transplanted with 2000 non-encapsulated canine islets under the kidney capsule $(\bigcirc ; n=5)$ or $500(\square ; n=7)$ and 1000 $(\square ; n=10)$ encapsulated canine islets in the intraperitoneal cavity. Values are compared to aged-matched normal controls ; $n=9)$ and expressed as means \pm SEM. Statistical significance of differences was calculated by one-way analysis of variance. ${ }^{\mathrm{a}} p<0.05 ;{ }^{\mathrm{b}} p<0.01$ vs control

100 days after transplant (Fig. 2). Compared to agematched normal controls, animals implanted with 2000 non-encapsulated islets under the kidney capsule showed significantly lower $(p<0.01)$ glucose values at 0,30 and 60 min during the OGTT. When recipients of 500, 1000, 2000 and 4000 encapsulated islets placed intraperitoneally were compared, their blood glucose levels were similar and also similar to agematched normal controls; there were no statistical differences between them at any time points during the OGTT (Fig. 2; data represent recipients of 500 and 1000 encapsulated islets only). When animals in the 2000 non-encapsulated (kidney capsule) group were compared with recipients of encapsulated islets, their glucose values were lower at $0 \mathrm{~min}(p<0.05$ vs 500 , 1000 and 2000 islets), $15 \mathrm{~min}$ ( $p<0.01$ vs 500 islets) 

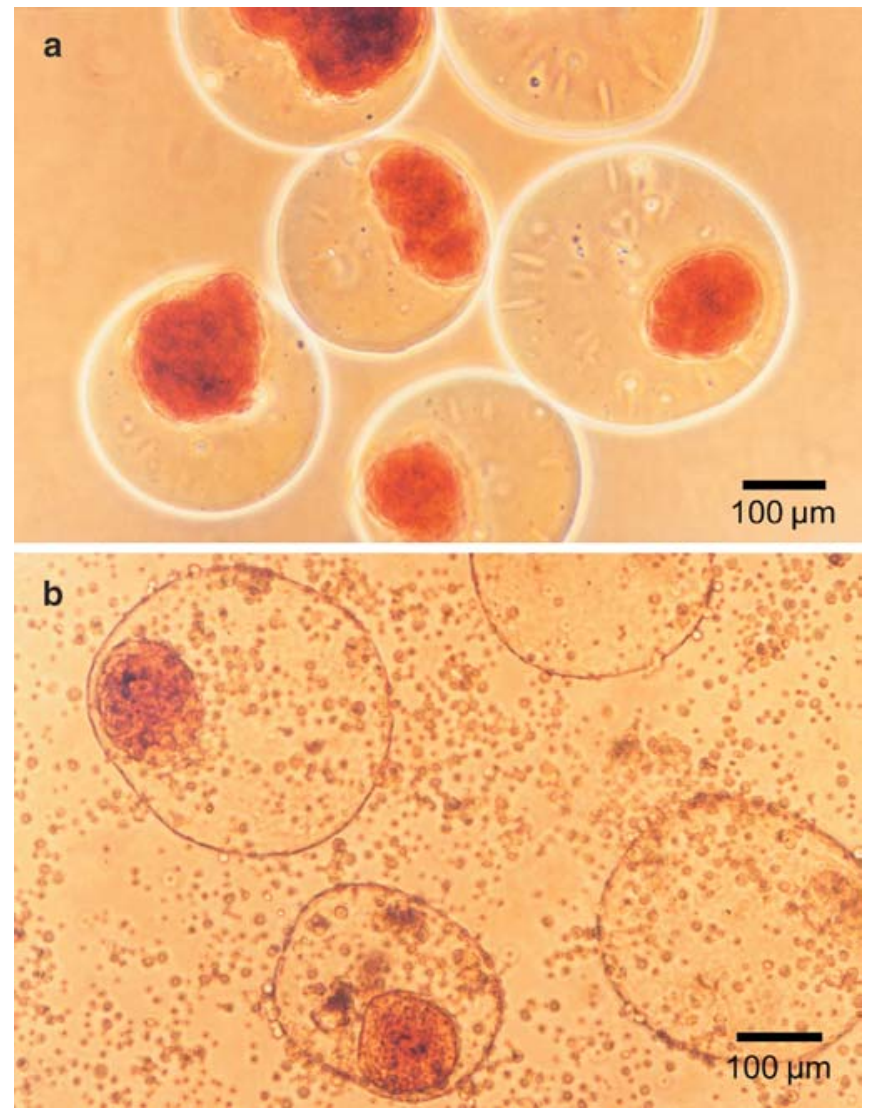

Fig. 3. Light micrographs of dithizone-stained encapsulated canine islets before (a) and after (b) implantation into the peritoneum of alloxan-induced diabetic nude mice

and at $30 \mathrm{~min}$ ( $p<0.05$ vs 500,1000 and 2000 islets). In all groups, glycaemia at $120 \mathrm{~min}$ was not significantly different from values at $0 \mathrm{~min}$.

Examination of recovered encapsulated canine islets at 100 days or longer after transplantation revealed structurally intact capsules and islets with no signs of capsule breakage or fibrotic reaction on the capsule surface (Fig. 3). In all the recipients of nonencapsulated islets, removal of the graft-bearing kidney was followed by a rapid return to the diabetic state. The pancreatic insulin content of recipients of encapsulated islets was less than $2 \%(<0.6 \mu \mathrm{g})$ that of normal nude mice $(38.9 \pm 1.8 \mu \mathrm{g})$. These results demonstrate that the normoglycaemia observed in these recipients was attributable to insulin production from the encapsulated islet grafts and not from residual pancreatic beta cells.

Syngeneic transplantation of mouse islets. Syngeneic $\mathrm{BALB} / \mathrm{c}$ mouse islet grafts were transplanted to test the ability of encapsulated islets to normalise the diabetic state in immunocompetent animals and to observe the biocompatibility of our alginate. All animals implanted with either 500 non-encapsulated (kidney capsule) or encapsulated (intraperitoneal) islets exhibited normalisation of blood glucose levels
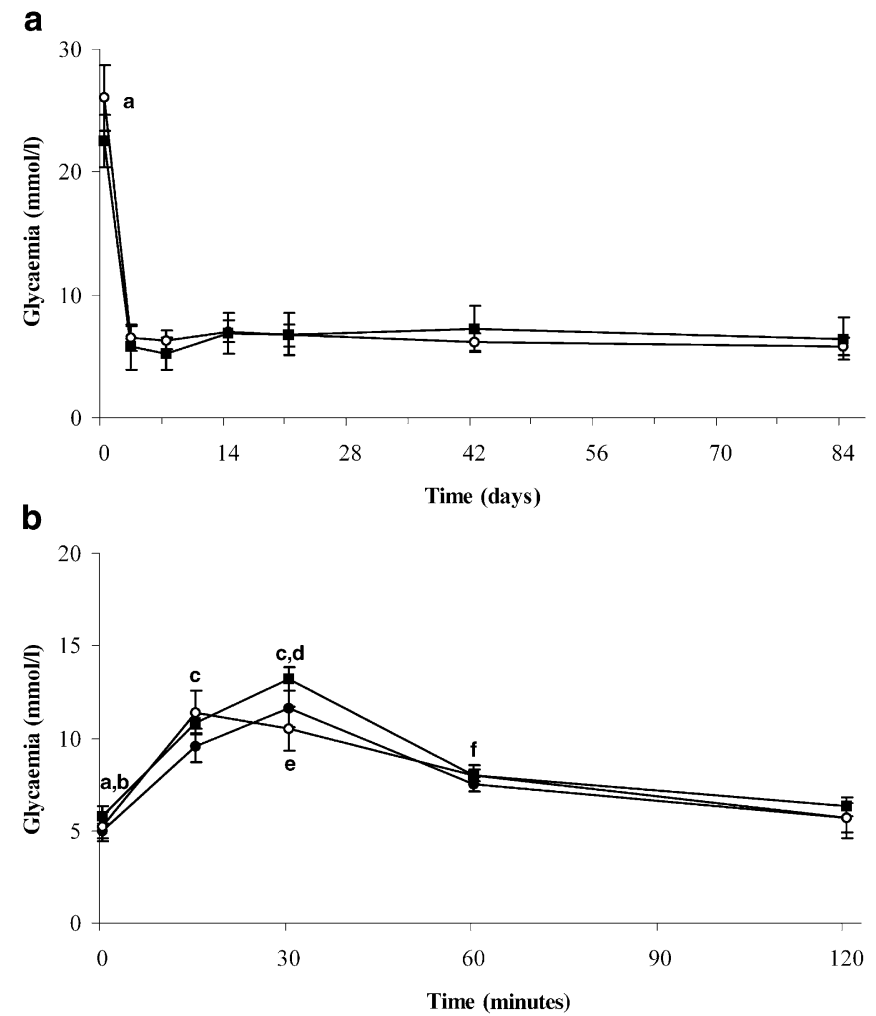

Fig. 4. Function of syngeneic pancreatic islet grafts in alloxaninduced diabetic BALB/c mice. Grafts consisted of 500 nonencapsulated $(\bigcirc ; n=6$; kidney capsule) or microencapsulated ( $\boldsymbol{\square} ; n=11$; intraperitoneal) syngeneic islets. a. Non-fasting blood glucose concentrations are shown from the time of transplantation (day 0) to the conclusion of the follow-up period ${ }^{\mathrm{a}} p<0.001$. b. Blood glucose values during an OGTT in normal control BALB/c mice $(\mathbf{O} ; n=5)$ and those transplanted with 500 non-encapsulated $(\bigcirc ; n=6 ;$ kidney) or encapsulated $(\square ; n=7$; intraperitoneal) syngeneic islets. Values are expressed as means \pm SEM. ${ }^{b} p<001$ vs non-encapsulated kidney; ${ }^{c} p>0.001$ vs control; ${ }^{\mathrm{d}} p>0.001$ vs non-encapsulated kidney; e $p<0.002$ vs control; ${ }^{\mathrm{f}} p<0.001$ vs control (analysis of variance)

$(<8.4 \mathrm{mmol} / \mathrm{l})$ within $48 \mathrm{~h}$ after the transplant (Fig. 4a). This metabolic state was maintained over the 150-day follow-up period with no significant differences between the two groups (Fig. 4a). An OGTT was performed on normoglycaemic recipients and age-matched normal controls at approximately 150 days after the transplant (Fig. 4b). Compared to normal controls, animals implanted with either nonencapsulated (kidney capsule) or encapsulated (intraperitoneal) islets showed comparable glucose values at all time points throughout the OGTT. Furthermore, removal of the graft-bearing kidney at the end of the study resulted in a rapid return to hyperglycaemia and all pancreases from encapsulated islet recipients contained negligible insulin $(<0.5 \mu \mathrm{g})$. 


\section{Discussion}

This study examined whether microencapsulation with a highly-purified alginate preserves islet survival and function during long-term tissue culture, as well as after transplantation into immune-competent and immune-deficient animals. Initial experiments assessed canine islet survival and insulin secretory responsiveness after long-term tissue culture. Once these experiments demonstrated excellent function and survival in vitro, encapsulated canine islets were then transplanted into diabetic nude mice to determine metabolic function and the minimal mass required to achieve euglycaemia. An immuno-incompetent nude mouse model was chosen in order to exclude the effects of rejection, thereby accurately examining the metabolic function of the islet grafts. Syngeneic mouse islet transplants were also conducted to test the biocompatibility of the grafts and the ability to achieve euglycaemia and glucose tolerance. Using a syngeneic model allowed us to observe any potential effects the alginate might have on the graft, given that syngeneic tissue itself would not specifically elicit an immune response.

When non-encapsulated canine islets were cultured at $22{ }^{\circ} \mathrm{C}$ for 1 week, islet recovery decreased significantly and when the culture period was extended to 2 and 3 weeks, recovery of non-encapsulated canine islets was further reduced. However, when canine islets were encapsulated islet loss during culture was much lower, with recoveries of $70 \%$ after 3 weeks. After these culture periods, glucose-stimulated insulin secretion was assessed. Similar amounts of insulin were secreted from both non-encapsulated and encapsulated islets cultured for 1 week. Moreover, both non-encapsulated and encapsulated canine islets maintained their glucose responsiveness after 1 week at $22{ }^{\circ} \mathrm{C}$ since their insulin secretory activity remained comparable to freshly isolated islets (data not shown). After 2 and 3 weeks of culture, the insulin secretion at high glucose concentrations was comparable, however the calculated stimulation indices for non-encapsulated islets were significantly decreased. This lower response was a direct result of higher basal release of insulin at low glucose $(2.8 \mathrm{mmol} / \mathrm{l})$, which would suggest that extended culture induces beta cell injury causing passive discharge of insulin and ultimately an abnormal secretory capacity. This reduction of islet function was also observed in the poor ability of nonencapsulated islets cultured for 2 or 3 weeks to correct diabetes in nude mice, whereas encapsulated islets cultured for up to 3 weeks achieved euglycaemia in $75 \%$ to $100 \%$ of the animals for 100 days or longer. Mice receiving encapsulated islets also showed normal glucose tolerance, though, interestingly, they showed somewhat lower blood glucose levels at various points along the OGTT than age-matched normal controls. While excess beta cell mass might explain this finding, we feel that this observation was the result of the donor canine beta cells regulating the recipient's glucose homeostasis to the level found in dogs, rather that that found in mice. In other words, glucose homeostasis was regulated to the lower set point of the transplanted dog islets.

This comparative study on recovery and function of long-term cultured canine islets demonstrates that microencapsulation with highly purified alginate can be successfully used for storage of islet grafts for prolonged periods without a significant loss of islet cell mass or function. This technique maintains higher islet yields and functional viability both in vitro and post-transplantation than conventional suspension tissue culture. This protective effect may be achieved because microencapsulation provides an environment that mimics the anatomical three-dimensional pancreatic matrix structure, preventing islet deterioration and preserving survival and functional viability. Other studies have similarly shown that extracellular matrices play a significant role in inducing islet growth and differentiation $[25,26]$. Preservation of individual islets within a microcapsule also offers an advantage over conventional culture by preventing islet aggregation, which often causes central necrosis of these large cellular aggregates. Furthermore, the ability to maintain islets in long-term culture is useful for clinical islet transplantation, as it permits the combination of isolates from multiple donors in order to achieve a critical beta cell mass, as well as offering the opportunity to manipulate the tissue prior to transplantation.

We also compared the success and longevity of varying masses of encapsulated or non-encapsulated canine islets. Renal subcapsular transplantation of 1000 non-encapsulated canine islets failed to correct hyperglycaemia in the majority of recipients, whereas $83 \%$ of the animals achieved normoglycaemia when the mass was increased to 2000 islets. In contrast, when 2000 or 4000 non-encapsulated islets were implanted intraperitoneally, only one of 17 recipients exhibited normoglycaemia for longer than a day. This latter observation was expected, as previous studies have reported that the intra-peritoneum is not an effective site for non-encapsulated islet grafts [27]. In fact, intraperitoneal transplantation with encapsulated islets has also shown problems, with cellular overgrowth of the capsules [28], immune system sensitisation [29] and an inability of encapsulated islets to sense glucose concentration changes [30]. In the present study, however, long-term normoglycaemia was obtained when 500 or more encapsulated islets were transplanted into the peritoneum, with the majority of recipients remaining euglycaemic for 100 days or more and exhibiting comparable glucose tolerance curves to normal controls. To our knowledge, this is the first report demonstrating that encapsulated islets transplanted intraperitoneally cannot only reproducibly achieve euglycaemia but also normal glucose tolerance. 
Finally, grafts consisting of 500 encapsulated $\mathrm{BALB} / \mathrm{c}$ mouse islets transplanted intraperitoneally also reproducibly achieved euglycaemia for 150 days after transplantation. Blood glucose values for these animals were not significantly different than those obtained from animals transplanted with non-encapsulated syngeneic islets under the kidney capsule. Furthermore, both of these groups of animals showed normal glucose tolerance during an OGTT at 150 days, when compared with age-matched controls. Since syngeneic islets will elicit no host response, and given that there were no appreciable differences between our groups, we concluded that the alginate used in these experiments is biocompatible since no detrimental effect was observed.

In all of the above experiments, the encapsulated grafts exhibited no fibrotic overgrowth at 100 days or longer after transplant. Much of the overgrowth of fibroblasts on capsules in other studies can be attributed to the effects of poly-L-lysine [15] or impurities in the alginate [12]. The complete absence of fibroblasts on the alginate capsules in our experiments, however, may be a result of the high purity of the alginate, thereby contributing to its improved biocompatibility. This may also explain why a lower mass of encapsulated canine islets placed intraperitoneally (i.e. 1000 islets) was more effective at achieving normoglycaemia than non-encapsulated control islets transplanted under the kidney capsule (i.e. 2000 islets). Since islets placed under the kidney capsule tend to fuse together forming large clumps, these grafts may be exposed to more hypoxic conditions resulting in necrosis and/or apoptosis [31]. Furthermore, encapsulation of islets, while not providing a perfect immune barrier, certainly may prolong graft survival $[6,32]$. While the exclusion of poly-L-lysine from our alginate capsule increases the porosity of the capsule [33], the capsule retains the ability to prevent contact of host cells such as macrophages with the islets, ultimately extending graft survival [34]. Nonetheless, an open pore alginate capsule is not so much an immune barrier as a support matrix to enhance islet viability, which is a critical essential step before a perm-selective membrane is placed on the islet. The ability of these capsules to so successfully restore glucose responsiveness may largely be a result of the high purity and low endotoxin content of the alginate $[6,32]$. Therefore, microencapsulating islets with an alginate of excellent biocompatibility can provide an environment that supports long-term islet graft survival and function, ultimately reducing beta cell loss and dysfunction in the immediate post-transplant period.

This study demonstrates that a purified alginate can be successfully used for long-term storage of islet grafts. This approach succeeds in maintaining higher islet yields and functional viability than conventional suspension tissue culture. It is also encouraging that transplantation of islet grafts microencapsulated with purified alginate into a non-vascularised site such as the peritoneal cavity permits grafts to not only correct basal glycaemia but also achieve normal glucose tolerance. Furthermore, it is encouraging that these grafts have the ability to provide long-term reversal of hyperglycaemia without any observable host reaction to the alginate.

Acknowledgements. Support was provided by the Canadian Diabetes Association, Canadian Institutes of Health Research, Alberta Heritage Foundation for Medical Research, Edmonton Civic Employees Charitable Assistance Fund, MacLachlan Fund, and Metabolex. We would like to acknowledge Karl Enevold for his role in the purification of the alginate. A. G. Mallett is a recipient of scholarships from the Canadian Institutes of Health Research and the Alberta Heritage Foundation for Medical Research. G. S. Korbutt is a recipient of a Juvenile Diabetes Research Foundation Career Development Award and is an Alberta Heritage Foundation for Medical Research Senior Scholar.

\section{References}

1. Shapiro AM, Lakey JR, Ryan EA et al. (2000) Islet transplantation in seven patients with type 1 diabetes mellitus using a glucocorticoid-free immunosuppressive regimen. $\mathrm{N}$ Engl J Med 343:230-238

2. Zhao M, Christie MR, Heaton N, George S, Amiel S, Cai HG (2002) Amelioration of streptozotocin-induced diabetes in mice using human islet cells derived from longterm culture in vitro. Transplantation 73:1454-1460

3. Schmied BM, Ulrich A, Matsuzaki H et al. (2000) Maintenance of human islets in long-term culture. Differentiation 66:173-180

4. Tatarkiewicz K, Garcia M, Lopez-Avalos M, Bonner-Weir S, Weir GC (2001) Porcine neonatal pancreatic cell clusters in tissue culture: benefits of serum and immobilization in alginate hydrogel. Transplantation 71:1518-1526

5. Ao Z, Korbutt GS, Warnock GL, Flashner M, Colby CB, Rajotte RV (1995) Microencapsulation enhances canine islet survival during long-term culture. Transplant Proc 27:3350

6. Duvivier-Kali VF, Omer A, Parent RJ, O’Neil JJ, Weir GC (2001) Complete protection of islets against allorejection and autoimmunity by a simple barium-alginate membrane. Diabetes 50:1698-1705

7. Ryan EA, Lakey JR, Paty BW et al. (2002) Successful islet transplantation: continued insulin reserve provides longterm glycemic control. Diabetes 51:2148-2157

8. Zimmermann U, Thurmer F, Jork A et al. (2001) A novel class of amitogenic alginate microcapsules for long-term immunoisolated transplantation. Ann NY Acad Sci 944:199-215

9. Sun Y, Ma X, Zhou D, Vacek I, Sun AM (1996) Normalization of diabetes in spontaneously diabetic cynomologus monkeys by xenografts of microencapsulated porcine islets without immunosuppression. J Clin Invest 98:1417-1422

10. Lanza RP, Ecker DM, Kuhtreiber WM, Marsh JP, Ringeling J, Chick WL (1999) Transplantation of islets using microencapsulation: studies in diabetic rodents and dogs. J Mol Med 77:206-210

11. Van Schilfgaarde R, De Vos P (1999) Factors influencing the properties and performance of microcapsules for immunoprotection of pancreatic islets. J Mol Med 77:199-205

12. King A, Andersson A, Strand BL, Lau J, Skjak-Braek G, Sandler S (2003) The role of capsule composition and bio- 
logic responses in the function of transplanted microencapsulated islets of Langerhans. Transplantation 76:275-279

13. De Vos P, De Haan B, Pater J, Van Schilfgaarde R (1996) Association between capsule diameter, adequacy of encapsulation, and survival of microencapsulated rat islet allografts. Transplantation 62:893-899

14. Bunger CM, Gerlach C, Freier T et al. (2003) Biocompatibility and surface structure of chemically modified immunoisolating alginate-PLL capsules. J Biomed Mater Res 67A:1219-1227

15. Strand BL, Ryan TL, In't VP et al. (2001) Poly-L-Lysine induces fibrosis on alginate microcapsules via the induction of cytokines. Cell Transplant 10:263-275

16. King A, Lau J, Nordin A, Sandler S, Andersson A (2003) The effect of capsule composition in the reversal of hyperglycemia in diabetic mice transplanted with microencapsulated allogeneic islets. Diabetes Technol Ther 5:653-663

17. Klock G, Frank H, Houben R et al. (1994) Production of purified alginates suitable for use in immunoisolated transplantation. Appl Microbiol Biotechnol 40:638-643

18. Wandrey C, Vidal DS (2001) Purification of polymeric biomaterials. Ann NY Acad Sci 944:187-198

19. Halle JP, Bourassa S, Leblond FA et al. (1993) Protection of islets of Langerhans from antibodies by microencapsulation with alginate-poly-L-lysine membranes. Transplantation 55:350-354

20. Warnock GL, Cattral MS, Rajotte RV (1988) Normoglycemia after implantation of purified islet cells in dogs. Can J Surg 31:421-426

21. Yakimets WJ, Lakey JR, Yatscoff RW et al. (1993) Prolongation of canine pancreatic islet allograft survival with combined rapamycin and cyclosporine therapy at low doses. Rapamycin efficacy is blood level related. Transplantation 56:1293-1298

22. Ricordi C, Gray DW, Hering BJ et al. (1990) Islet isolation assessment in man and large animals. Acta Diabetol Lat 27:185-195

23. Ohzato H, Gotoh M, Monden M, Dono K, Kanai T, Mori T (1991) Improvement in islet yield from a cold-preserved pancreas by pancreatic ductal collagenase distention at the time of harvesting. Transplantation 51:566-570

24. Korbutt GS, Elliott JF, Ao Z, Smith DK, Warnock GL, Rajotte RV (1996) Large scale isolation, growth, and function of porcine neonatal islet cells. J Clin Invest 97:21192129
25. Bonner-Weir S, Taneja M, Weir GC et al. (2000) In vitro cultivation of human islets from expanded ductal tissue. Proc Natl Acad Sci USA 97:7999-8004

26. Beattie GM, Rubin JS, Mally MI, Otonkoski T, Hayek A (1996) Regulation of proliferation and differentiation of human fetal pancreatic islet cells by extracellular matrix, hepatocyte growth factor, and cell-cell contact. Diabetes 45:1223-1228

27. De Vos P, Hillebrands JL, De Haan BJ, Strubbe JH, Van Schilfgaarde R (1997) Efficacy of a prevascularized expanded polytetrafluoroethylene solid support system as a transplantation site for pancreatic islets. Transplantation 63:824-830

28. King A, Sandler S, Andersson A, Hellerstrom C, Kulseng B, Skjak-Braek G (1999) Glucose metabolism in vitro of cultured and transplanted mouse pancreatic islets microencapsulated by means of a high-voltage electrostatic field. Diabetes Care 22 [Suppl 2]:B121-B126

29. Orlowski T, Godlewska E, Moscicka M, Sitarek E (2003) The influence of intraperitoneal transplantation of free and encapsulated Langerhans islets on the second set phenomenon. Artif Organs 27:1062-1067

30. Del Guerra S, Bracci C, Nilsson K et al. (2001) Entrapment of dispersed pancreatic islet cells in CultiSpher-S macroporous gelatin microcarriers: preparation, in vitro characterization, and microencapsulation. Biotechnol Bioeng 75:741-744

31. Davalli AM, Scaglia L, Zangen DH, Hollister J, BonnerWeir S, Weir GC (1996) Vulnerability of islets in the immediate posttransplantation period. Dynamic changes in structure and function. Diabetes 45:1161-1167

32. Omer A, Duvivier-Kali VF, Trivedi N, Wilmot K, BonnerWeir S, Weir GC (2003) Survival and maturation of microencapsulated porcine neonatal pancreatic cell clusters transplanted into immunocompetent diabetic mice. Diabetes 52:69-75

33. Martinsen A, Skjak-Baek G, Smidsrod O (1989) Alginate as immobilization material: I. Correlation between chemical and physical properties of alginate. Biotechnol Bioeng 33:79-89

34. Wu G, Korsgren O, Zhang J, Song Z, Van Rooijen N, Tibell A (2000) Pig islet xenograft rejection is markedly delayed in macrophage-depleted mice: a study in streptozotocin diabetic animals. Xenotransplantation 7:214-220 